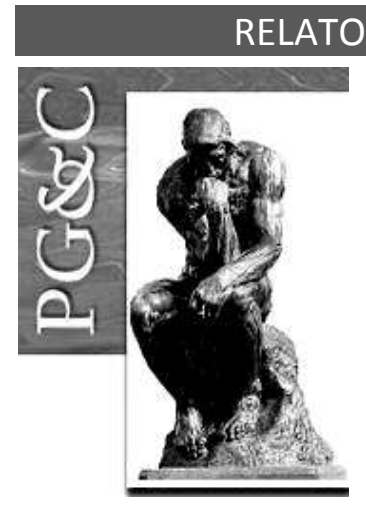

\title{
MODELO DE GESTÃO E A MEMÓRIA ORGANIZACIONAL NA INDÚSTRIA CERVEJEIRA ARTESANAL DO RIO GRANDE DO SUL
}

\author{
Leonardo Jacques \\ Mestre em Indústria Criativa pela Universidade Feevale, Brasil. Professor \\ do Centro Universitário Leonardo da Vinci, Brasil. \\ E-mail: ljacques@terra.com.br \\ Dusan Schreiber \\ Doutor em Administração pela Universidade Federal do Rio Grande do Sul, \\ Brasil. Professor da Universidade Feevale, Brasil. \\ E-mail: dusan@feevale.br \\ Moema Pereira Nunes \\ Doutora em Administração pela Unisinos, Brasil. Professora da \\ Universidade Feevale, Brasil. \\ E-mail: moemanunes@hotmail.com \\ Vanessa Theis \\ Doutora em Qualidade Ambiental pela Universidade Feevale, Brasil. \\ Professora da Universidade Feevale, Brasil. \\ E-mail: vanessat@feevale.br
}

\begin{abstract}
Resumo
Este artigo objetiva analisar o modelo de gestão e as evidências de memória organizacional em cervejarias pertencentes à Rota das Cervejarias Artesanais no estado do Rio Grande do Sul. A pesquisa caracteriza-se como qualitativa e descritiva, adotando-se como procedimentos o estudo de casos múltiplos. Os dados empíricos foram coletados por meio de entrevistas narrativas com profissionais de empresas produtoras de cerveja artesanal, como mestres cervejeiros e sommeliers. A pesquisa foi complementada com a observação não participante in loco e a pesquisa documental. Os dados foram submetidos à análise de conteúdo, no sentido de evidenciar como ocorre a Gestão e as particularidades referentes à memória organizacional das referidas empresas. Como principais resultados, destaca-se que em termos de gestão, o padrão mais observado é aquele em que a sociedade é composta pelos membros de família ou por indivíduos de elevado grau de afetividade e confiança mútua. Ademais, foram identificadas evidências de memória organizacional, representando não só o início da história das cervejarias, mas servindo, também, como referência para manutenção dos valores do presente e para projeção de estratégias futuras.
\end{abstract}

Palavras-chave: Microempresas. Modelo de Gestão. Memória Organizacional. Cerveja Artesanal.

\section{MANAGEMENT MODELS AND THE ORGANIZATIONAL MEMORY IN THE ARTISANAL BREWERY INDUSTRY OF RIO GRANDE DO SUL}

\begin{abstract}
This paper aims to analyze the management process and the evidence of organizational memory in breweries belonging to the Rota das Cervejarias Artesanais in the state of Rio Grande do Sul. It is characterized as qualitative and descriptive, adopting the study of multiple cases as procedures. Empirical data were collected through narrative interviews with professionals from craft beer production
\end{abstract}

Perspectivas em Gestão \& Conhecimento, João Pessoa, v. 11, n. 1, p. 65-80, jan./abr. 2021. DOI: http://dx.doi.org/10.22478/ufpb.2236-417X.2021v11n1.55133

http://periodicos.ufpb.br/ojs2/index.php/pgc. ISSN: 2236-417X. Publicação sob Licença (cc)) EY-NC-ND 
companies, such as master brewers and sommeliers. The research was complemented with nonparticipant observation and documentary research. The data were submitted to content analysis, in order to show how management occurs and the particularities related to the organizational memory of these companies. As main results, it is highlighted that in terms of management, the most observed pattern is one in which society is composed of family members or individuals with a high degree of affection and mutual trust. In addition, evidence of organizational memory was identified, representing not only the beginning of the history of the breweries, but also serving as a reference for maintaining the present values and for projecting future strategies.

Keywords: Micro-companies. Management model. Organizational Memory. Craft Beer.

\section{INTRODUÇÃO}

Com a chegada dos imigrantes alemães, a cerveja passou a adquirir posição de destaque entre as bebidas consumidas no Brasil. A colonização deste grupo étnico no Rio Grande do Sul tem como data originária o ano de 1824, quando se tem o registro da instalação da primeira colônia de imigrantes na região denominada de Vale dos Sinos. O isolamento territorial das colônias dificultava o acesso aos produtos originários dos centros urbanos, de tal forma que se tornou primordial para sua população a produção de determinados bens voltados a sua subsistência. $O$ surgimento desta necessidade contribuiu para a constituição de cervejarias familiares como forma para suprir as demandas locais (DE PAULA SANTOS, 2003).

É comum, neste contexto, os imigrantes se apegarem aos seus saberes e formar grupos que buscam reproduzir suas tradições culturais, com destaque para a produção de cerveja. De Paula Santos (2003) ressalta que a organização produtiva cervejeira familiar representa uma situação de apego e resistência no Rio Grande do Sul criada pelos imigrantes alemães. Logo, a cerveja desenvolve no imaginário deste grupo étnico um vínculo com outro espaço e tempo, construindo uma ressignificação do seu próprio ser, e, até mesmo, uma reafirmação da identidade em um processo de reconstrução simbólica e cultural das suas origens.

Com base neste encadeamento histórico, Alstete e Meyer (2020) destacam que a memória organizacional está relacionada ao conjunto de informações geradas como consequência de decisões implementadas, processos realizados, lembranças individuais e interpretações compartilhadas, facultando o aumento da competitividade e sustentabilidade organizacional, por meio da reutilização de informações e conhecimentos. Spiller e Pontes (2007), corroboram que as experiências pelas quais passa uma organização são acumuladas, ao longo dos anos, nas suas pessoas, cultura, processos e em seus documentos, e esse conjunto de conhecimentos forma a sua memória.

Neste sentido, pensando na realidade das empresas do setor cervejeiro do Rio Grande do Sul, este artigo busca responder a seguinte questão de pesquisa: Quais são as características do modelo de gestão e as evidências de memória organizacional em cervejarias pertencentes à Rota das Cervejarias Artesanais no estado do Rio Grande do Sul? A problemática de estudo constitui-se desta forma, pois, em uma primeira visita ao campo de pesquisa, observou-se que os proprietários de cervejarias artesanais se apoiam, na composição de seus negócios, em origens e laços familiares.

Ressalta-se que para a Associação Brasileira de Bebidas (ABRABE, 2020), as microcervejarias produzem cerveja ou chope especial em pequenas quantidades, sendo em sua quase totalidade de origem familiar. Para Morado (2009) muitas microcervejarias começam como uma empresa familiar e assim permanecem atendendo ao mercado local e regional, mantendo o controle da família no negócio. No intuito de responder ao problema de

Perspectivas em Gestão \& Conhecimento, João Pessoa, v. 11, n. 1, p. 65-80, jan./abr. 2021. 
pesquisa, o objetivo do artigo consiste em analisar o modelo de gestão e as evidências de memória organizacional em cervejarias pertencentes à Rota das Cervejarias Artesanais no estado do Rio Grande do Sul. Tais evidências representam não só o início da história das cervejarias, mas também servem como referência para manutenção dos valores do presente e para projeção do seu futuro.

Cumpre destacar que, em 2018, o governo do Estado do Rio Grande do Sul, por meio da Lei 15.098 criou a Rota das Cervejarias Artesanais, com a intenção de fortalecer o turismo, gerar emprego e renda, e valorizar a produção gaúcha no segmento. A composição da rota é de 22 cidades, sendo que destas, mais de $50 \%$ pertencem a região do Vale dos Sinos. A partir de 2014, 19 novas cervejarias foram criadas na região, sendo que sete se localizam na cidade de Novo Hamburgo (MAPA, 2019).

Em termos metodológicos, este estudo possui abordagem qualitativa e descritiva e como estratégia de pesquisa o estudo de casos múltiplos. Os dados foram coletados nas empresas investigadas por meio de entrevistas narrativas aos seus profissionais, observação não-participante e da pesquisa documental. Assim, por apresentar dados empíricos, coletados diretamente com os sujeitos que atuam no ambiente corporativo em análise, a contribuição central do estudo, diz respeito as características gerenciais do modelo de gestão e as evidências de memória organizacional em cervejarias pertencentes à Rota das Cervejarias Artesanais no estado do Rio Grande do Sul?

Como principais resultados, destaca-se em termos de gestão, o padrão mais observado é aquele em que a sociedade é composta com a presença de membros de família ou por indivíduos de elevado grau de afetividade e confiança mútua. Com relação as evidências de memória organizacional, verificou-se que estas representam não só o início da história das cervejarias, mas também servem como referência para manutenção dos valores do presente e para projeção de estratégias futuras. Destaca-se que, esta pesquisa se justifica em função da relevância histórica do segmento para a região, bem como em função do crescimento deste modelo de negócio, com o número de novas marcas e estabelecimentos produtores aumentando anualmente, gerando novos empregos e fortalecendo a economia.

Após esta introdução, esta pesquisa apresenta a seguinte estrutura: a contextualização da gestão de microempresas familiares e as características da memória organizacional. A seguir, são elencados os procedimentos metodológicos, e, por fim, expõe-se as análises e discussões dos resultados. Após a descrição e apresentação do corpus pesquisado, estão descritas as considerações finais em relação ao objetivo, suas contribuições, limitações e sugestões para investigações futuras.

\section{REFERENCIAL TEÓRICO}

Nesta seção, discute-se a gestão de microempresas familiares, seguido do tema memória, em razão de ser um dos motivadores para esta pesquisa, e pelo fato de seus conceitos constituírem o filtro interpretativo da realidade observada nas microempresas familiares. Com o propósito de proporcionar maior entendimento sobre o campo de pesquisa, contextualiza-se o setor de cervejas artesanais.

\subsection{MODELOS DE GESTÃO EM MICROEMPRESAS FAMILIARES}

A empresa familiar pode ser considerada uma das mais antigas formas de negócio que surgiu ao longo da evolução da humanidade, sendo que a mais comum é a propriedade rural (DALBOSCO; ZITKOSKI, 2005). Para Williams (2018), a empresa familiar se caracteriza pela sucessão do poder decisório da maneira hereditária a partir de uma ou mais famílias, criada pela figura de um empreendedor. Conforme Leite (2017), o poder de comando deverá ser

Perspectivas em Gestão \& Conhecimento, João Pessoa, v. 11, n. 1, p. 65-80, jan./abr. 2021. 
transferido paulatinamente pelo dono para o herdeiro sucessor, e para que isso ocorra, de forma tranquila e exitosa, o novo líder precisa ter o perfil e as condições necessárias à efetiva administração do negócio, sem contestação dos antigos dirigentes.

Um menor número de produtores de cerveja, por questões mercadológicas, incorpora novos investidores ou profissionais para dar a continuidade do negócio. Civera, Cortese e Fiandro (2018), corroboram essa afirmação ao verificar que, em pesquisa desenvolvida junto a empresas familiares produtoras de cerveja, parte da amostra apresentou desempenho mercadológico muito acima da média setorial para aquele perfil de empresas. Upton, Teal e Felan (2001) investigaram as razões para esse fenômeno e observaram que o grupo com desempenho baixo ou mediano era restrito a pessoas do núcleo familiar, isto é, não utilizavam gestores externos à família, não realizavam planejamento estratégico formal e não apresentavam relatórios e informações sobre a empresa.

Por outro lado, as empresas pertencentes ao grupo que apresentou alto crescimento e desempenho mercadológico realizavam as atividades de planejamento estratégico com frequência, com horizonte de tempo variando entre um e três anos. Além disso, as empresas deste grupo contratavam gestores oriundos do mercado (não pertencentes à família) para atividades de gestão e planejamento, e também divulgavam informações e relatórios de gestão entre os stakeholders da organização (UPTON; TEAL; FELAN, 2001)

De acordo com a Associação Brasileira de Bebidas (ABRABE, 2020), outro fator que contribui para definição de cervejarias artesanais como empresas familiares é que microcervejarias são microindústrias com modestas instalações que proporcionam a produção de cerveja ou chope especial em pequenas quantidades e, que em sua quase totalidade têm origem familiar. Ademais, Duarte, Lourenço e Fontana (2020) ressaltam que muitas microcervejarias começam como uma empresa familiar e assim permanecem, atendendo ao mercado local e regional, mantendo o controle da família no negócio, como acontece em alguns países europeus. Já outras se expandem e se transformam em cervejarias industriais.

Segundo Ceribeli, Merlo e Morais (2010), muitas pequenas empresas, cuja condução dos negócios estava concentrada nos sócios e de maneira informal, cresceram e atingiram um nível no qual a gestão familiar e informal não mais é eficiente e suficiente. Assim, os proprietários perceberam a necessidade de profissionalizar sua gestão, preparando-as para continuar a crescer. Constatou-se que uma estrutura administrativa mais profissional facilita a implementação de ações e práticas de gestão mais modernas.

Lussier e Sonfield (2004) listam dois modelos que caracterizam as empresas familiares no tocante à forma de gestão: o primeiro, paternalístico; e, o segundo, profissional. O modelo paternalístico é caracterizado pelas relações hierárquicas, controle do poder e autoridade do dirigente, proximidade de supervisão e desconfiança em membros externos, que não pertencem à família. $O$ modelo profissional envolve não só a inclusão, como também certa predominância de membros externos à família em posição de direção, mais abertos para novos conhecimentos, conceitos de inovação e tecnologia embarcada.

Sobre empresas familiares, pode-se mencionar também a presença da memória na valorização de sua história, em seu passado. Bernhoeft e Gallo (2003) apresentam características em que é possível observar tal afirmação, a saber: (1) a valorização da antiguidade ou tempo de serviço; (2) os laços afetivos que influenciam comportamentos e decisões; (3) a valorização da confiança mútua (4) as dificuldades em separar emocional e racional; (5) a expectativa de que os funcionários sejam altamente dedicados e fiéis à organização e seus valores.

Realizadas considerações a respeito da gestão de microempresas familiares, apresenta-se a seguir a revisão sobre memória organizacional.

Perspectivas em Gestão \& Conhecimento, João Pessoa, v. 11, n. 1, p. 65-80, jan./abr. 2021. 


\subsection{MEMÓRIA ORGANIZACIONAL}

A temática acerca da memória organizacional possui várias implicações e abordagens. Neves e Cerdeira (2018) sinalizam que não há consenso sobre a definição do conceito de memória organizacional, nem sobre a realidade designada pelo mesmo ou, tampouco, sobre o nível em que esta pode ou não se reconhecer nas práticas das organizações. Em outras palavras, o fenômeno pode ser entendido no contexto dos indivíduos e dos grupos ou no nível dos processos organizacionais ou no nível das metáforas organizacionais, que se tornam úteis para a compreensão de algumas especificidades das organizações.

Stein (1995) entende que a memória organizacional se refere aos meios pelos quais se busca o conhecimento sobre a experiência do passado para incorporar e dar suporte às atividades do presente, a fim de obter maior eficácia organizacional. Logo, a memória de uma organização é entendida como um sistema instrumental de gestão de informação, baseado na aquisição, conservação, manutenção, pesquisa e recuperação de informações relevantes para a gestão dos processos organizacionais. Os autores Walsh e Ungson (1991) corroboram que a memória organizacional é a informação armazenada da história da organização, que pode ser aplicada em decisões presentes. Neste sentido, essa informação é armazenada como consequência de implementação de decisões a que referem, por meio de recordações individuais e de interpretações compartilhadas.

Conforme Spiller e Pontes (2007), as experiências pelas quais passa uma organização são acumuladas, ao longo dos anos, nas suas pessoas, cultura, processos e em seus documentos, e esse conjunto de conhecimentos forma a sua memória. Neste contexto, Conklin (1996), complementa que a memória organizacional amplia o conhecimento por capturar, organizar, divulgar e reutilizar o conhecimento criado pelos colaboradores. Neste sentido, Freire et al. (2012) complementam que, sendo a memória organizacional preservada, esta contribui para que os procedimentos de experiências que deram certo possam ser retomados, acrescentando novos conhecimentos, evitando e aprendendo com os erros já cometidos.

Menezes (2006), complementa que a memória organizacional reúne o acervo de informações, conhecimentos e práticas, agregados e retidos pela organização ao longo de sua existência, utilizados para o suporte às suas atividades, seus processos decisórios e para a preservação do seu capital intelectual, potencializando a Gestão do Conhecimento. De acordo com Antunes e Pinheiro (2019), memória organizacional é o conhecimento corporativo que representa experiências prévias arquivadas e compartilhadas pelos usuários, sendo constituída por conhecimento explícito e conhecimento tácito, e abrange aspectos funcionais, técnicos e sociais de trabalho, o trabalhador e o ambiente de trabalho.

Os autores Hatami et al. (2003), corroboram que a memória organizacional visa a preservação do conhecimento e que possibilita guardar conhecimento tácito, além de apoiar os processos de decisão. Para Abecker (1998) uma das principais funções da memória organizacional é aumentar a competitividade da organização, pelo aperfeiçoamento da forma como ela gerencia seu conhecimento.

De forma complementar, Yagui (2003) esclarece que a memória organizacional pode ser considerada um instrumento de apoio organizacional, visto que objetiva a preservação da memória técnica, gerencial e de negócios, além de ser uma fonte de aprendizado organizacional, de valor agregado, e que possibilita vantagem competitiva frente ao ambiente de negócios, no qual as empresas atuam. Dessa forma, procura-se desenvolver um processo que faça com que a organização utilize seu capital intelectual, que são baseados em conhecimento, e que estejam armazenados em documentos, bases de dados ou outros tipos de repositórios, agregando valor aos seus produtos e serviços, levando à inovações e vantagens competitivas acerca de seus concorrentes. Para tanto, a organização deve estar

Perspectivas em Gestão \& Conhecimento, João Pessoa, v. 11, n. 1, p. 65-80, jan./abr. 2021. 
atenta ao desenvolvimento de ações que visem detectar os conhecimentos que possui, e criar mecanismos de explicitação e retenção desse conhecimento.

Entretanto, os esforços em desenvolver e implantar uma base de conhecimentos não trará resultados se a mesma não for atualizada constantemente, visto que seu valor está relacionado com sua atualização. Neste sentido, Yagui (2003) sinaliza que a contribuição para a atualização do repositório da memória organizacional deve ser objetivo de todos os colaboradores, assim como aos meios de compartilhamento de conhecimento devem ser constantemente estimulados, considerados como uma ação estratégica organizacional, a fim de trazer o retorno desejado. Contudo, Almeida (2006) alerta que as atividades da memória organizacional, devem estar inseridas nas tarefas rotineiras, de forma que não sejam vistas como um trabalho adicional ou fora da rotina de trabalho, do contrário, podem ter o empenho do colaborador comprometido e prejudicado.

Totini e Gagete (2004) citam que, no Brasil, o estudo da memória organizacional surgiu por meio da iniciativa de acadêmicos na década de 1960, interessados na reflexão sobre a estrutura e a evolução industrial brasileira, ao buscar compreender a relação entre os aspectos econômicos, a ideologia e a estrutura das empresas. Na visão das autoras, diversas empresas e instituições utilizaram-se de projetos de memória empresarial como ferramenta de gestão estratégica, no que se refere ao autoconhecimento necessário às tomadas de decisão do presente e ao planejamento do futuro, ou até mesmo para construção de políticas de relacionamento com seus players.

\subsection{O SETOR DE CERVEJAS ARTESANAIS}

Em 2013, as cervejas especiais representavam 10\% do mercado brasileiro, e, para 2020, a expectativa era chegar a $20 \%$, segundo projeção realizada pelo Sindicato Nacional da Indústria da Cerveja (SINDICERV, 2018). Um fator que contribui para visualização do crescimento da indústria cervejeira artesanal é a geração de empregos. De acordo com dados compilados pela Associação Brasileira de Cerveja Artesanal (ABRACERVA) e o Cadastro Geral de Empregados e Desempregados (CAGED), em 2018, as cervejarias artesanais geraram 54\% dos empregos no setor. $O$ destaque vai para as cervejarias artesanais independentes com até quatro colaboradores, que foram responsáveis por 800 novos postos de trabalho. Entre os estados, Minas Gerais liderou o ranking, com 278 vagas, seguido por Rio Grande do Sul (111) e Santa Catarina (92).

Dados do Ministério da Agricultura, Pecuária e Abastecimento (MAPA, 2019), apresentados no Anuário da Cerveja de 2019, revelam que os estados de São Paulo e Rio Grande do Sul, apresentaram, respetivamente, 241 e 236 cervejarias registradas naquele ano, liderando o ranking nacional. Os números indicam um crescimento de estabelecimentos no estado do Rio Grande do Sul na faixa de 28,9\% entre os anos de 2017, 2018 e 2019, respectivamente 142, 186 e 236 unidades em cada ano.

O Rio Grande do Sul lidera os índices de densidade cervejeira, com uma cervejaria para cada 48 mil habitantes, enquanto a média nacional é de 173 mil pessoas por cervejaria. 0 anuário revela ainda que o índice de densidade aumenta ainda mais em cidades com menos de 100 mil habitantes, evidenciando o grande impacto que a cultura cervejeira tem nos municípios pequenos, destacando que o Rio Grande do Sul possui 6 dos 10 municípios com maior densidade cervejeira no Brasil. No que diz respeito ao registro de novos produtos, a cerveja continua sendo o produto mais frequente no MAPA alcançando o número de 9.950 registros, bem à frente do segundo lugar, polpa de fruta, com 2.535, seguido de vinho, com 1.676 registros, a bebida alcoólica mista, 1.251, suco, 1.094 e cachaça com 857 registros. O Rio Grande do Sul desponta como o Estado com maior número de registros, seguido pelo estado de São Paulo.

Perspectivas em Gestão \& Conhecimento, João Pessoa, v. 11, n. 1, p. 65-80, jan./abr. 2021. 
Outro ponto que estimula esse mercado no estado do Rio Grande do Sul é o fator turístico. Em 2018, o governo do Estado, por meio da Lei 15.098 criou a Rota das Cervejarias Artesanais, com a intenção de fortalecer o turismo, gerar emprego e renda, e valorizar a produção gaúcha no segmento. A composição da rota é de 22 cidades, sendo que destas, mais de $50 \%$ pertencem a região do Vale dos Sinos. A referida região possui cultura germânica onde se iniciaram as primeiras produções de cerveja no Rio Grande do Sul, em 1824. A partir de 2014, 19 novas cervejarias foram criadas na região, sendo que sete se localizam na cidade de Novo Hamburgo (MAPA, 2019).

\section{MÉTODO DE PESQUISA}

Utilizou-se o método qualitativo e descritivo para a condução desta pesquisa, adotando-se como procedimentos o estudo de casos múltiplos. Os dados foram coletados nas empresas investigadas por meio de entrevistas narrativas aos seus profissionais, observação não-participante e da pesquisa documental. O campo de pesquisa, foram as empresas da Rota das Cervejas Artesanais do Rio Grande do Sul. Ressalta-se que a Lei 15.098 de 4 de janeiro de 2018, no artigo 82, inciso IV, da Constituição do Estado do Rio Grande, institui que a Região das Cervejarias Artesanais é composta pelos municípios da Rota Romântica e pelos seguintes municípios: Alto Feliz, Campo Bom, Feliz, Igrejinha, São Vendelino, Sapiranga, Três Coroas e Vale Real. De acordo com Associação Brasileira de Bebidas (2020), um projeto multiplataforma sobre as cervejas produzidas no Rio Grande do Sul, a Rota das Cervejas contempla 107 empresa.

Dentro deste universo, foram selecionadas sete empresas do setor estudado, de forma não probabilística, intencional e por conveniência, adotando critérios de acessibilidade e disponibilidade de tempo dos entrevistados. Em relação ao volume de produção, todas as unidades investigadas estiveram dentro da faixa de 20.000 litros/mês, capacidade média de produção indicada para cervejarias artesanais (SEBRAE, 2015). No Quadro 1 constam as informações relativas ao tempo de atuação no mercado, localização geográfica, volume de produção mensal e a função exercida pelos profissionais das empresas investigadas.

Quadro 1 - Resumo Sobre as Unidades de Análise

\begin{tabular}{|c|c|c|c|c|}
\hline Cervejaria & $\begin{array}{c}\text { Tempo da } \\
\text { Empresa }\end{array}$ & Localização & $\begin{array}{c}\text { Volume de } \\
\text { Produção }\end{array}$ & Função Entrevistado \\
\hline 1 & 8 anos & Novo Hamburgo & 6.000 litros / mês & Mestre Cervejeiro \\
\hline 2 & 2 anos & Novo Hamburgo & 12.000 litros / mês & $\begin{array}{c}\text { Mestre } \\
\text { Cervejeiro/Sommelier }\end{array}$ \\
\hline 3 & 2 anos & Campo Bom & 8.000 litros / mês & Mestre Cervejeiro \\
\hline 4 & 3 anos & Novo Hamburgo & 6.000 litros / mês & Técnologo \\
\hline 5 & 3 anos & Novo Hamburgo & 5.000 litros / mês & Sommelier \\
\hline 6 & 8 anos & Nova Petrópolis & 20.000 litros / mês & Mestre Cervejeiro \\
\hline 7 & 7 anos & Novo Hamburgo & 8.000 litros/mês & Proprietário \\
\hline
\end{tabular}

As entrevistas foram realizadas entre os meses de setembro e outubro de 2019 , sendo gravadas e posteriormente transcritas por um dos autores. Cada uma das entrevistas durou, em média, 45 minutos e foi realizada nas instalações das cervejarias. Foi realizado o contato com os profissionais, para agendar o encontro para compartilhar os resultados da pesquisa. Para determinar a quantidade de informações coletadas, utilizou-se o critério de saturação, ou 
seja, quando os entrevistados passaram a repetir o conteúdo obtido anteriormente, sem acréscimo de informações relevantes à pesquisa (EISENHARDT, 1989).

O roteiro de entrevistas, que foi desenvolvido a partir do referencial teórico e, considerando o estilo de entrevista aplicado, do tipo narrativa, o mesmo foi composto por questões abertas. Segundo Moura e Nacarato (2017) as entrevistas narrativas representam um dispositivo de produção e análise de dados para pesquisas que, pela sua peculiaridade na geração de textos narrativos, tem aproximação com abordagens autobiográficas, e busca romper com a rigidez imposta pelas entrevistas estruturadas e/ou semiestruturadas.

Para fins de validação, o roteiro foi submetido à apreciação de dois pesquisadores da área de gestão, cujas contribuições foram utilizadas para fins de refinamento do instrumento. Foram conduzidas duas rodadas de validação com cada especialista. O número de rodadas depende, normalmente, da natureza do grupo e sua homogeneidade, sendo que a seleção dos experts é considerada não aleatória, por conveniência e intencional e se justifica uma vez que o interesse é selecionar especialistas na temática de estudo (WRIGHT; JOHNSON; BIAZZI, 1991; KAYO; SECURATO, 1997).

Além disto, foram realizadas visitas as cervejarias escolhidas como unidade de análise para verificação in loco, com intuito de melhor entender o que foi mencionado durante as entrevistas. Destaca-se que estas duas etapas ocorreram no mesmo dia. Ressalta-se que a pesquisa documental complementou os dados coletados nas entrevistas e na observação direta. Foram consultados os relatórios de produção dos últimos dois anos e as empresas se propuseram a mostrar parte de seu planejamento organizacional, apresentando os planos elaborados para estabelecimento de parcerias, detalhando o processo das capacitações de seus funcionários, e demonstrando, até mesmo, os valores de faturamento, despesas e custos.

Também foram consultados os registros históricos das empresas (recortes de jornal, divulgação das empresas em diferentes canais de mídia, arquivos de fotos e até mesmo vídeos e entrevistas concedidas pelos proprietários e seus familiares) que proporcionaram uma visualização mais apurada da relevância da memória organizacional neste segmento.

A análise dos dados seguiu as recomendações de Bardin (2011), que sugere compreender as características, estruturas ou modelos que estão por trás dos fragmentos de mensagens tornados em consideração. A análise foi elaborada, sendo apresentada a seguir, seguindo as categorias de análise definidas previamente a partir da literatura revisada, conforme pode ser verificado no Quadro 2.

Quadro 2 - Categorias de Análise

\begin{tabular}{|c|c|c|}
\hline & $\begin{array}{c}\text { Modelo de Gestão nas Cervejarias } \\
\text { Artesanais }\end{array}$ & Evidências da Memória Organizacional \\
\hline Autores & $\begin{array}{l}\text { Upton, Teal e Felan (2001); Bernhoeft e } \\
\text { Gallo (2003); Lussier e Sonfield (2004); } \\
\text { Dalbosco e Zitkoski (2005); Leite (2017); } \\
\text { Williams (2018); Cortese e Fiandro (2018); } \\
\text { Duarte, Lourenço e Fontana (2020), }\end{array}$ & $\begin{array}{l}\text { Walsh e Ungson (1991); Stein (1995); } \\
\text { Abecker (1998); Conklin (2001); Hatami et } \\
\text { al. (2003); Yagui (2003); Menezes (2006); } \\
\text { Almeida (2006); Spiller e Pontes (2007); } \\
\text { Freire et al. (2012); Antunes e Pinheiro } \\
\text { (2019). }\end{array}$ \\
\hline
\end{tabular}

Fonte: Dados da pesquisa (2020)

Cumpre destacar que a análise categorial na análise dos textos obtidos das transcrições das entrevistas, isto é, a organização e síntese dos dados qualitativos resultam na obtenção de categorias que contém a essência do discurso dos entrevistados. Para a operacionalização deste processo, os autores realizaram o desmembramento do texto nas categorias supramencionadas, no software Excel. Além disto, foi utilizada a análise textual, a

Perspectivas em Gestão \& Conhecimento, João Pessoa, v. 11, n. 1, p. 65-80, jan./abr. 2021. 
fim de aprofundar a compreensão dos fenômenos que investiga a partir de análise criteriosa, não pretendendo testar hipóteses, para comprová-las ou refutá-las ao final da pesquisa.

\section{APRESENTAÇÃO E ANÁLISE DE RESULTADOS}

A análise dos resultados inicia com uma contextualização da indústria cervejeira no Vale dos Sinos e dos elementos estruturantes do modelo de gestão das cervejarias analisadas. $\mathrm{Na}$ sequência são investigados os aspectos relacionados à memória organizacional evidenciados ao longo da coleta de dados.

\subsection{O MODELO DE GESTÃO NAS CERVEJARIAS ARTESANAIS}

De acordo com os resultados auferidos por meio das entrevistas, é possível perceber que, na indústria cervejeira artesanal da região em estudo, as relações familiares e de afeto entre os dirigentes são predominantes, confirmando o conceito da Abrabe (2019) que define cervejarias artesanais como empresas familiares. Segundo esse órgão, microcervejarias são microindústrias com modestas instalações que proporcionam a produção de cerveja ou chope especial em pequenas quantidades e, que, em sua quase totalidade, têm origem familiar.

Conceitualmente, Lussier e Sonfield (2004) listam dois modelos que caracterizam as empresas familiares no tocante à forma de gestão, o paternalístico e o profissional, sendo o modelo paternalístico caracterizado pelas relações hierárquicas, controle do poder e autoridade do dirigente, proximidade de supervisão e não confiança em "estranhos" (membros externos não pertencentes à família). Em contrapartida, o modelo profissional envolve não só a inclusão, como também certa predominância de membros externos à família em posição de direção, mais abertos para novos conhecimentos, conceitos de inovação e modernidade.

Pode-se perceber que o modelo paternalístico é o mais presente na gestão de todas as cervejarias entrevistadas. Desde a fundação dos negócios, a administração segue centralizada em integrantes da família ou por meio de sociedade de amigos que possuem uma relação de afeto de longa data e com expressivos níveis de confiança mútua.

Há exemplos em que os entrevistados manifestaram de forma explícita que não há intenção em fazer mudanças em sua estrutura, preservando a sua configuração inicial, como na afirmação do entrevistado 6 :

Não, não, sem problema, 'vamos lá'... Eu classifico nosso modelo de gestão como familiar, pois seguimos da forma como abrimos a empresa, nós dois tocando o negócio com as posições definidas... Não tem uma outra gestão de pessoas de fora... E acredito que a maioria é assim... E não, não pensamos em mais sócios!

De acordo com Duarte, Lourenço e Fontana (2020), muitas microcervejarias começam como uma empresa familiar e assim permanecem atendendo ao mercado local e regional, mantendo o controle da família no negócio. Esse ponto também pode ser observado na afirmação do entrevistado 1:

A família trabalha diretamente no negócio, e não há sócios. Não há interesse em ser maior, queremos continuar atendendo esse nosso público de amigos aqui da região. Só não será mais nosso se vier alguém que compre o negócio!

Perspectivas em Gestão \& Conhecimento, João Pessoa, v. 11, n. 1, p. 65-80, jan./abr. 2021. 
Houve também situações em que se cogitou iniciar o empreendimento com uma composição profissional, no entanto, como pôde ser visto no depoimento do entrevistado 7, a partir da estabilidade atingida nos processos de produção e comercial, e no funcionamento da cervejaria de forma geral, a opção principal foi manter a gestão somente com a família:

...um amigo de longa data me propôs: "Vamos ser sócios: tu fabrica e eu vou comercializar!". E aquilo foi rolando a conversa a semana inteira e eu digo: "Tá bom, julho vai ter o primeiro lote, e aí vamos... ou seja, seis meses eu quero me preparar, buscar informação, cursos que deve fazer, curso on-line, presencial, que seja, e em julho tu vai ter o primeiro lote pra nós, pra nós ver se vai dar certo esse negócio!".

Efetivamente, no início da segunda quinzena de julho tava pronta a primeira cerveja.

...esse meu sócio informal daquele momento, ele tinha comprado a segunda companhia de exportação dele, e ele tava mergulhado em uma série de dificuldades e ajustes do tempo dele, então ele não podia abrir uma terceira linha de negócios, e ele precisou de uns dois anos, me disse: "Eu vou precisar de uns dois anos pra botar as empresas a ponto de novo e depois a gente faz a sociedade!". Efetivamente, claro, continuamos conversando, tomando chopp, e dois, três anos depois ele disse: "Julio, agora eu já estou com tempo pra tocar o nosso projeto". Mas aí eu disse: Bah, lamento, agora eu já juntei o barro, a empresa tá andando, a gente tem muitas dificuldades que tem que superar, sobretudo na parte de marketing, em que eu nunca fiz muita força, é, tanto é que a cervejaria não é muito conhecida, mas também em um primeiro momento foi uma estratégia de negócio, e enfim... até a um mês atrás mais ou menos ele me disse: "Não quer mesmo que eu seja teu sócio?" E eu digo: “Não, obrigado, eu gosto de trabalhar sozinho!”. O que eu devo fazer é colocar minha filha para me ajudar no marketing, e depois ir assumindo aos poucos, naturalmente... acredito que ela tem bom perfil, tem capacidade, já está se envolvendo... e eu confio! E ela gosta do negócio.

Os comentários do entrevistado 7 corroboram o entendimento do conceito de Leite (2017), ao destacar que o poder de comando deverá ser transferido paulatinamente pelo dono para o herdeiro sucessor, e para que isso suceda de forma tranquila, constante e perene, o novo líder (ou sucessor) precisa ter o perfil e as condições necessárias à efetiva administração do negócio, sem contestação dos antigos dirigentes.

Finalizadas as observações referentes ao modelo de gestão aplicados na indústria cervejeira artesanal, na sequência serão apresentadas evidências da memória organizacional neste setor, por meio de exemplos descritos pelos profissionais entrevistados.

\subsection{EVIDÊNCIAS DA MEMÓRIA ORGANIZACIONAL}

Ao longo da pesquisa, identificou-se uma série de evidências da presença de memória organizacional na indústria cervejeira artesanal, por meio de histórias e experiências compartilhadas pelos empresários e colaboradores. Conforme Spiller e Pontes (2007), as experiências pelas quais passa uma organização são acumuladas, ao longo dos anos, nas suas pessoas, cultura, processos e em seus documentos e identidade, e esse conjunto de conhecimentos forma a sua memória. O comentário do entrevistado 1 reforça a referida constatação: 
Muitos não acreditavam na possibilidade de sucesso da fabricação, logo citaram que a cerveja ficaria uma 'bosta', e então, acrescentamos um ' $s$ ' a mais, dando origem a BOSSTA. Hoje, sou conhecido pela minha experiência no ramo, e carinhosamente chamado por algumas pessoas como o Sr. BOSSTA.

Segundo os relatos dos entrevistados, observou-se inclusive a formação da identidade das cervejarias, no momento em que os entrevistados descrevem símbolos, personagens e até mesmo mascotes, que acompanham lembranças e consequentemente evidenciam a memória organizacional. Estes símbolos são descritos a seguir, pelo entrevistado 2, e, na sequência, pelo entrevistado 5.

Eu citaria o próprio logo do Alce, que acompanha a cervejaria desde sua fundação, estampando inclusive os rótulos de três das nossas cervejas PILSEN, BLOND ALE e AMERICAN AMBAR ALE, nosso mascote de pelúcia que acompanha todos os eventos (um bebê Alce usando uma camiseta da cervejaria) e uma mensagem subliminar que está em todos os rótulos e nos itens da loja, a qual caberá ao público procurar e fazer sua descoberta. Citaria também nossa hashtag \#apreciecervejaslocais. Acho de fundamental importância, pois traz uma identidade para a cervejaria, bem como fortalece a ligação entre a equipe.

Ainda se torna um elemento que colabora com a história de vida da empresa e com quem os consumidores possam se identificar.

A mascote é legal, porque remete a toda nossa história. Quando a gente começou, a Kira (nome da pequena pitbull que é mascote) estava sempre por perto, então já colocamos ela como marca, e hoje todo mundo reconhece. Já faz parte da história.

Para o entrevistado 2 e o entrevistado 5, a participação nesta pesquisa contribuiu de forma a retomar, registrar - ou escrever - sobre elementos que, mesmo presentes no contexto organizacional, quando não lembrados podem perder força, e futuramente até serem esquecidos, corroborando os conceitos de Walsh e Ungson (1991), os quais entendem que a memória organizacional é a informação armazenada da história da organização. O comentário do entrevistado 3 reforça esse conceito:

... é ótimo poder falar sobre tudo isso de novo, em um trabalho... tem coisas que se a gente não repete pra alguém, daqui a pouco até acaba esquecendo. É bom pra retomar toda nossa história!

Em termos conceituais, Stein (1995) entende que a memória organizacional se refere aos meios pelos quais se busca o conhecimento sobre a experiência do passado para incorporar e dar suporte às atividades do presente, a fim de obter maior eficácia organizacional. Associado a este conceito tem-se o comentário do entrevistado 6 , bem como a imagem do rótulo indicado durante seu comentário na Figura 1:

...sobre a questão da produção de lúpulo: Um dia nós soubemos que havia uma plantação de lúpulo aqui em Nova Petrópolis, da década de 50, abandonada, e que foi restaurada, inclusive com o auxílio da EMATER, que foi consultada. Fomos falar com um senhor de 80 anos sobre isso. Lançamos um produto específico com este lúpulo.

A outra é que, uma vez por semana, eu almoço na casa da minha vó... A gente queria fazer uma cerveja com gosto de casca de bergamota, de laranja, e um dia fomos no pé da casa da minha vó para pegar algumas e produzir a cerveja. O rótulo da cerveja tem a figura da minha vó... A 
reportagem da BAND (Bandeirantes) foi filmar a vó, e ela disse "nunca pensei que seria garota propaganda de alguma coisa com 80 anos.

Figura 1 - Rótulo de cerveja com casca de bergamota

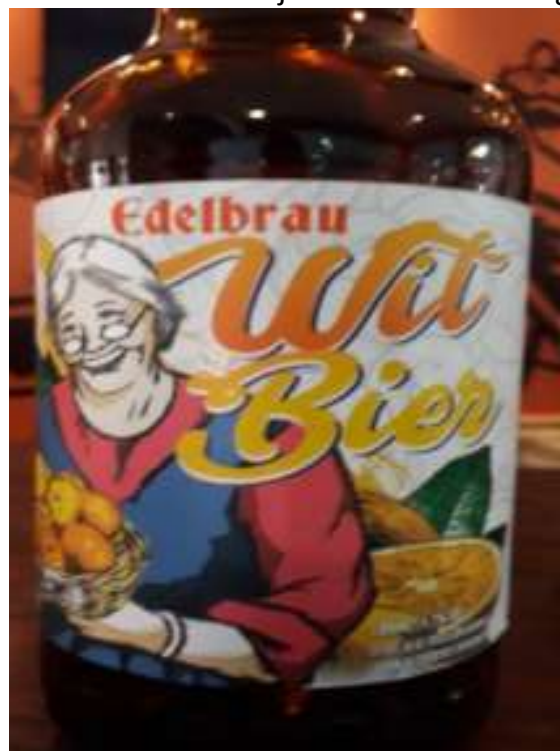

Fonte: Acervo do entrevistado unidade de análise 6

Os relatos efetuados pelos entrevistados, com a descrição de histórias de família e a referência a elementos como mascotes, personagens e símbolos das cervejarias ajudam a evidenciar a presença de memória organizacional nas cervejeiras e fortalecem as bases conceituais de Yagui (2003) e Hatami et al. (2003), visto que, pôde-se verificar que criam mecanismos que operacionalizam o conhecimento tácito em inovação de produtos.

No Quadro 3 é apresentada uma síntese com considerações feitas por parte dos entrevistados em relação às categorias de análise e as fontes utilizadas para a realização da pesquisa.

Quadro 3 - Resumo das considerações dos entrevistados sobre as categorias de análise

\begin{tabular}{|c|c|c|}
\hline & $\begin{array}{c}\text { Modelo de Gestão nas Cervejarias } \\
\text { Artesanais }\end{array}$ & Evidências da Memória Organizacional \\
\hline Entrevistado 1 & $\begin{array}{l}\text { Gestão familiar e que segue com a } \\
\text { mesma estrutura desde a abertura da } \\
\text { empresa. Não pensa em sócios. } \\
\text { Mudanças de estrutura apenas se } \\
\text { vender o negócio. }\end{array}$ & $\begin{array}{l}\text { Nome da cervejaria está diretamente } \\
\text { relacionado a uma história envolvendo o } \\
\text { proprietário e amigos. }\end{array}$ \\
\hline Entrevistado 2 & $\begin{array}{l}\text { Gestão familiar, mas com acréscimo na } \\
\text { estrutura de indivíduos com alto grau } \\
\text { de confiança em cargos não diretivos } \\
\text { (como por exemplo, embaixador da } \\
\text { marca). }\end{array}$ & $\begin{array}{l}\text { Símbolos estão estampados nos rótulos das } \\
\text { cervejas, e o mascote é reconhecido pelos } \\
\text { clientes e acompanha a equipe em eventos. }\end{array}$ \\
\hline Entrevistado 3 & $\begin{array}{l}\text { Gestão familiar, embora a maior } \\
\text { concentração de trabalho esteja no } \\
\text { fundador. Parentes auxiliam, mas à } \\
\text { distância. }\end{array}$ & $\begin{array}{l}\text { Proprietário costuma tomar decisões com } \\
\text { base em fatos ocorridos no passado. }\end{array}$ \\
\hline Entrevistado 4 & $\begin{array}{l}\text { Gestão realizada por indivíduos com } \\
\text { elevado grau de confiança. Sem } \\
\text { interesse por novos sócios. }\end{array}$ & $\begin{array}{l}\text { Proprietário costuma tomar decisões com } \\
\text { base em fatos ocorridos no passado. }\end{array}$ \\
\hline
\end{tabular}

Perspectivas em Gestão \& Conhecimento, João Pessoa, v. 11, n. 1, p. 65-80, jan./abr. 2021. 


\begin{tabular}{|c|c|c|}
\hline Entrevistado 5 & $\begin{array}{l}\text { Gestão realizada por indivíduos com } \\
\text { elevado grau de confiança. Sem } \\
\text { interesse por novos sócios. }\end{array}$ & $\begin{array}{l}\text { Mascote que deu nome à cervejaria é } \\
\text { considerado um dos elementos importantes } \\
\text { para o resultado da cervejaria. }\end{array}$ \\
\hline Entrevistado 6 & $\begin{array}{l}\text { Gestão familiar, que segue com a } \\
\text { mesma estrutura desde a abertura da } \\
\text { empresa. Não pensa em ter mais } \\
\text { sócios no futuro. }\end{array}$ & $\begin{array}{l}\text { Um dos produtos foi elaborado após a } \\
\text { lembrança de um fato histórico, relacionado } \\
\text { a um familiar de um dos proprietários. }\end{array}$ \\
\hline Entrevistado 7 & $\begin{array}{l}\text { Gestão familiar, sendo que o } \\
\text { proprietário aos poucos prepara uma } \\
\text { das filhas para assumir o negócio em } \\
\text { definitivo em um futuro próximo. }\end{array}$ & $\begin{array}{l}\text { Nome da cervejaria foi estabelecido de } \\
\text { acordo com a figura de um animal admirado } \\
\text { por uma das filhas (cavalo). }\end{array}$ \\
\hline Autores & $\begin{array}{l}\text { Lussier e Sonfield (2004), Duarte, } \\
\text { Lourenço e Fontana (2020), Dalbosco e } \\
\text { Zitkoski (2005), Leite (2017), Williams } \\
\text { (2018), Upton, Teal e Felan (2001), } \\
\text { Cortese e Fiandro (2018), Bernhoeft e } \\
\text { Gallo (2003). }\end{array}$ & $\begin{array}{l}\text { Walsh e Ungson (1991); Stein (1995); } \\
\text { Abecker (1998); Conklin (2001); Hatami et al. } \\
\text { (2003); Yagui (2003); Menezes (2006); } \\
\text { Almeida (2006); Spiller e Pontes (2007); } \\
\text { Freire et al. (2012); Antunes e Pinheiro } \\
\text { (2019). }\end{array}$ \\
\hline
\end{tabular}

Fonte: Os autores 2020

Concluída a etapa de análise dos resultados, na qual foram realizadas as relações entre as informações obtidas nas entrevistas da pesquisa de campo e no referencial teórico estudado sobre Gestão em Microempresas Familiares e Memória Organizacional, apresenta-se em seguida as considerações finais sobre a pesquisa realizada.

\section{CONSIDERAÇÕES FINAIS}

Este estudo se propôs a analisar o modelo de gestão e as evidências de memória organizacional em cervejarias pertencentes à Rota das Cervejarias Artesanais no estado do Rio Grande do Sul, e, para tal, definiu a aplicação de uma pesquisa com abordagem qualitativa, por meio do estudo de casos múltiplos. Os dados formam coletados por meio de entrevistas narrativas com profissionais de sete empresas produtoras de cerveja artesanal, como mestres cervejeiros e sommeliers. A pesquisa foi complementada com a observação não participante e a pesquisa documental. Os dados foram submetidos à análise de conteúdo, no sentido de evidenciar como ocorre a gestão e as particularidades referentes à memória organizacional das referidas empresas.

Por meio dos dados analisados, constatou-se que em termos de gestão, o padrão mais observado é aquele em que a sociedade é composta com a presença de membros de família ou por indivíduos de elevado grau de afetividade e confiança mútua. Por este motivo, pode-se dizer que o modelo paternalístico é o mais presente na gestão das cervejarias artesanais estudadas, afinal, desde a fundação dos negócios, a administração segue centralizada em integrantes da família, com movimentos sensíveis de transição para novas gerações (no caso das cervejarias onde a gestão é composta por indivíduos de confiança mútua, não há interesse por novos sócios).

Ademais, foram identificadas evidências de memória organizacional, sendo que, tais evidências representam não só o início da história das cervejarias, mas também servem como referência para manutenção dos valores do presente e para projeção de estratégias futuras. Entre estas evidências, constatou-se relatos que envolvem aspectos familiares, histórias que contemplam desde a abertura do negócio até o lançamento de produtos que até o presente momento são comercializados. Destaque também para mascotes e símbolos que compõem as logomarcas estampadas nas embalagens e rótulos, ou até mesmo para palavras consideradas "chave" e que dão nome ao estabelecimento. 
Ainda que esta pesquisa tenha atingido o objetivo proposto e que o rigor metodológico tenha sido perseguido, não se pode eximir a existência de limitações, que, no caso desta pesquisa, diz respeito ao número de casos analisados, o que, segundo a complexidade inerente do tema, sugere que possam surgir outras evidências, em outras organizações. Como recomendação de estudos futuros, ao final deste artigo, identificam-se oportunidades referentes a ampliação do escopo de pesquisa de forma a verificar a validade, por meio de um estudo quantitativo, os achados empíricos apresentados neste artigo. A referida pesquisa poderia ser realizada inicialmente no Rio Grande do Sul, podendo ser ampliada a outras regiões do Brasil.

\section{REFERÊNCIAS}

ABECKER, A. Toward a technology for organizational memories. IEEE Intelligent Systems and their Applications, v. 13, n. 3, p. 40-48, 1998.

ABRABE - Associação Brasileira de Bebidas. Site. Disponível em: < http://www.abrabe.org.br/categorias>. Acesso em: 15 nov. 2020.

ABRACERVA - Associação Brasileira de Cerveja Artesanal. Site. Disponível em: http://www.abracerva.com.br. Acesso em: 13 de nov. 2020.

ABRACERVA - Associação Brasileira de Cerveja Artesanal. Quantidade de Empregos Diretos RAIS, Lapolli C. in. Mercado da Cerveja 2019. Disponível em: < https://abracerva.com.br/rascunho-automatico/>. Acesso em: 21 maio 2020.

ALMEIDA, M. B. Um modelo baseado em ontologias para representação da memória organizacional. Minas Gerais. 2006. Tese (Doutorado em Ciência da Informação) - Universidade Federal de Minas Gerais, 2006.

ALSTETE, J. W.; MEYER, J. P. Intelligent agent-assisted organizational memory in knowledge management systems. VINE Journal of Information and Knowledge Management Systems, 2020.

ANTUNES, H. J. G.; PINHEIRO, P. G. Linking knowledge management, organizational learning and memory. Journal of Innovation \& Knowledge, 2019.

BARDIN, L. Análise de conteúdo. São Paulo: Edições 70, 2011.

BERNHOEFT, R.; GALLO, M. Governança na empresa familiar: gestão, poder e sucesso. Elsevier Brasil, 2003.

CERIBELI, H. B; MERLO, E. M; MORAIS, F.S. Análise do processo de profissionalização da gestão de empresas familiares atuantes no varejo. Revista Eletrônica de Ciência Administrativa, v. 9, n. 2, p. 233-250, nov. 2010.

CIVERA, C.; CORTESE, D.; FIANDRINO, S. Entrepreneurial Orientation and Family Influence Factors for Sustainable Small Business: First Insights From the Leading Italian Craft Beer Producer. In: Maintaining Sustainable Accounting Systems in Small Business. IGI Global, 2018. p. 215-236.

Perspectivas em Gestão \& Conhecimento, João Pessoa, v. 11, n. 1, p. 65-80, jan./abr. 2021. 
CONKLIN, J. Designing organizational memory: preserving intellectual assets in a knowledge economy. Group Decision Support Systems, v. 1, p. 362, 1996.

DALBOSCO, C; ZITKOSKI, D. M. Modelo de Gestão: Um estudo em empresas familiares. Revista de Administração, v. 4, n. 7, p. 17-47, dez. 2005.

DE PAULA SANTOS, S. Os primórdios da cerveja no Brasil. Atelie Editorial, 2003.

DUARTE, T.S.; LOURENÇO, W. M.; FONTANA, G. Origem, Ascensão e Decadência das Cervejarias no Estado do Rio Grande do Sul: Um Recorte Espaço-Temporal do Século XIX e XX. Caminhos de Geografia, v. 21, n. 73, p. 368-379-368-379, 2020.

EISENHARDT, K. M. Building Theories from Case Study Research. The Academy of Management Review, v. 14, n. 4, p. 532-550, 1989.

FREIRE, P. S.; BENETTI, T.T.K. C.; HELOU F., E. A.; da SILVA, G. G. Memória organizacional e seu papel na gestão do conhecimento. Revista de Ciências da Administração, vol. 14, n. 33, agosto, p. 41-51, 2012.

HATAMI, A.; GALLIERS, R. D.; HUANG, J. Exploring the impacts of knowledge (re) use and organizational memory on the effectiveness of strategic decisions: a longitudinal case study. In: 36th Annual Hawaii International Conference on System Sciences, 2003. Proceedings of the. IEEE, 2003. p. 11 pp.

LEITE, G. Processo de sucessão de empresas familiares e desafios da profissionalização. Revista Ciência Contemporânea, v. 1, n. 1, p. 35-60, 2017.

LUSSIER, R. N.; SONFIELD, M. C. Family business management activities, styles and characteristics: a correlational study. American Journal of Business, v. 19, n. 1, p. 47-53, 2004.

MAPA - Ministério Agricultura, Pecuária e Abastecimento. Anuário da cerveja no Brasil. 2019. Disponível em: http://www.cervbrasil.org.br/novo site/wpcontent/uploads/2020/03/anuario-cerveja-WEB.pdf. Acesso em: 21 maio 2020.

MENEZES, E. M. de. Estruturação da memória organizacional de uma instituição em iminência de evasão de especialistas: um estudo de caso na COHAB. Brasília: UCB, 2006. Dissertação (Mestrado em Gestão do Conhecimento e Tecnologia da Informação) Universidade Católica de Brasília, 2006.

MOURA, J. F.; NACARATO, A. M. A entrevista narrativa: dispositivo de produção e análise de dados sobre trajetórias de professoras. Cadernos de Pesquisa, v. 24, n. 1, p. 15-30, 2017.

MORADO, R. Larousse da Cerveja. São Paulo: Larousse, 2009.

NEVES, P. C.; CERDEIRA, J. P. Memória Organizacional, Gestão do Conhecimento e Comportamentos de Cidadania Organizacional. Perspectivas em Gestão \& Conhecimento, v. 8, n. 1, p. 3-19, 2018.

KAYO, E. K.; SECURATO, J. R. Método Delphi: fundamentos, críticas e vieses. Caderno de Pesquisa em Administração, São Paulo, v. 1, n. 4, pp. 51-61, abr. 1997.

Perspectivas em Gestão \& Conhecimento, João Pessoa, v. 11, n. 1, p. 65-80, jan./abr. 2021. 
Rio Grande do Sul (Estado). Lei no 15.098, de 4 de janeiro de 2018. Publicada no DOE no 4, de 5 de janeiro de 2018. Institui a Região das Cervejarias Artesanais no Estado do Rio Grande do Sul e dá outras providências. Disponível em: https://leisestaduais.com.br/rs/lei-ordinaria-n15098-2018-rio-grande-do-sul-institui-a-regiao-das-cervejarias-artesanais-no-estado-do-riogrande-do-sul-e-da-outras-providencias. Acesso em: 18 maio de 2020.

SEBRAE - SERVIÇO BRASILEIRO DE APOIO ÀS MICRO E PEQUENAS EMPRESAS. Relatório de Inteligência - Alimentos. Cerveja Artesanal. 2015. Disponível em: https://sebraeinteligenciasetorial.com.br/produtos/relatorios-de-inteligencia/cervejasartesanais/55c4ad3614d0c01d007ffeae. Acesso em: 30 abr. 2019.

SINDICERV - Sindicato Nacional da Indústria da Cerveja. 2018. Site. Disponível em: http://www.sindicerv.com.br. Acesso em: 26 fev 2020.

SPILLER; A.; PONTES, C. C. C. Memória organizacional e reutilização do conhecimento técnico em uma empresa do setor eletroeletrônico no Brasil. Rev. Brasileira de Gestão de Negócios, São Paulo, v. 9, n. 25, p. 96-108, set./dez. 2007.

STEIN, E. W. Organizational memory: Review of concepts and recomendations for management. International Journal of Information Management, v.15, n. 2, p.17-32, 1995.

TOTINI, B.; GAGETE, E. Memória empresarial, uma análise da sua evolução. In: NASSAR, P. (Org.). Memória de empresa: história e comunicação de mãos dadas, a construir o futuro das organizações. São Paulo: ABERJE, 2004. p. 113-126.

UPTON, N.; TEAL, E. J.; FELAN, J. T. Strategic and business planning practices of fast growth family firms. Journal of small business management, v. 39, n. 1, p. 60-72, 2001.

WALSH, J. P.; UNGSON, G. R. Organizational memory. Academy of Management Review, v. 16, n. 1, p. 57-91, 1991.

WILLIAMS J.R. R. I. Measuring family business performance: research trends and suggestions. Journal of Family Business Management, 2018.

WRIGHT, J. T.C; JOHNSON, B. B.; BIAZZI, J.L. O uso da técnica Delphi na elaboração de cenários. São Paulo, PETROBRÁS, 1991.

YAGUI, L. M. Memória organizacional: proposta para implantação em uma instituição de ensino superior. 2003. Dissertação (Mestrado em Engenharia de Produção) - Universidade Federal de Santa Catarina, Florianópolis, 2003.

Recebido em/Received: 10/09/2020 | Aprovado em/Approved: 07/01/2021 